\title{
Factors Affecting Time Spent Visiting Heritage City Areas
}

\author{
Esther Martinez-Garcia ${ }^{1, *(1)}$, Josep M. Raya-Vilchez ${ }^{2}$ (D) and Nuria Gali ${ }^{3}$ (D) \\ 1 Department of Economics and LMRT-Laboratori Multidisciplinar de Recerca en Turisme, \\ University of Girona, Plaça Ferrater Mora, 1, 17004 Girona, Spain \\ 2 Department of Economics and Statistics, University Pompeu Fabra-ESCET, Tecnocampus Mataró, \\ Avinguda Ernest Lluch, 32, 08302 Mataró (Barcelona), Spain; jmraya@tecnocampus.cat \\ 3 Department of Art History and LMRT-Laboratori Multidisciplinar de Recerca en Turisme, \\ University of Girona, Plaça Ferrater Mora, 1, 17004 Girona, Spain; nuria.gali@udg.edu \\ * Correspondence: esther.martinez@udg.edu; Tel.: +34-972-419-719
}

Received: 30 April 2018; Accepted: 29 May 2018; Published: 1 June 2018

check for updates

\begin{abstract}
Urban tourism is growing fast, and in many cities visitor influx tends to concentrate in historic urban centers. When there are large numbers of visitors, deepening the knowledge on visitor time consumption is critical to better managing their impact on the city, and creating a sustainable city tourism destination. This has generated an increasing interest in the micro-spatial and temporal dimensions of tourist behavior in city tourism research and planning. This article focuses on modelling the factors affecting the duration of visits to each heritage attraction, and to the whole visit to the heritage city. This study adds to previous research in several ways: it uses survival models; distinguishes between attractions with and without an entrance fee; and tests how visitor type affects time behavior, for example, day visitor versus tourists, peak season versus off-peak season, informed visitors versus non-informed visitors, highly motivated visitors versus visitors with low motivation. Results show that there is significant heterogeneity in time consumption. This is generated by factors such as traveling with children, cultural proximity, rating of the attraction, and price and time constraints. Some evidence is also found, which suggests first-time visitor and informed visitors have an impact on time consumption.
\end{abstract}

Keywords: time consumption; duration; historic attractions; sustainable heritage city; sustainable tourism planning

\section{Introduction}

Tourism is becoming a main source of economic activity in many cities worldwide. Regional growth is positively affected by domestic and international tourism [1]. Urban tourism is a fast-growing area, and in many cities visitor influx tends to be concentrated in the historic city centers [2]. Large numbers of visitors may exceed the carrying capacity of historic centers and generate sustainability issues that need strategies and actions to manage visitor congestion [3]. Large numbers of visitors may influence residents' attitudes to tourism development [4], and tourists need to have a satisfactory experience. Both visitors and the residents can gain from managing visitor flows and visitor attractions, and are key to sustainable destinations [5,6]. There is, therefore, a need for gaining knowledge of tourists' time consumption.

Knowledge of the total time spent visiting, and the determinants of the time spent at each attraction can be of great relevance for several reasons. Firstly, it enables better planning of that area of the city, for example, it can identify bottlenecks at the most popular attractions, and those that visitors spend longer visiting. It can also help develop more tailored and segmented site visiting 
packages, recommended tours and activities for tourists at each attraction in the heritage area [7]. For example, Grinberger et al. [8], in their analyses of individual tourist behavior, which considers socio-demographic characteristics of the tourist and time constraints, found that tourists generally valued the time spent on activities more than that spent on space. Heterogeneity in tourists visiting heritage sites has also called for more research on visitor's behavior at attractions [7-10].

This paper adds to existing literature on heritage and urban tourism sustainability [6] by providing empirical evidence on the time consumption of historical attractions, and its determinants in terms of characteristics of both tourists and the visit. By estimating the probability of visiting a specific attraction, and the time spent visiting each attraction and a group of attractions, as well as its determinants, this article answers the following questions: Which attractions (if any) can be considered "primary attractions", and which "secondary" attractions?; Is there evidence that the historic city center constitutes a cluster of secondary attractions, and how much time do tourists spend there?; does visitors' time consumption differ between attractions, and what factors influence heterogeneity in time consumption? Primary and secondary attractions are concepts stemming from attraction theory. Following Botti et al. [11], who offered an integrated approach to attraction theory, we consider that a primary attraction is one where the visitor spends longer time, as utility is positively associated with time consumption. In contrast, a secondary attraction is one where the visitor spends little time, as once the visitor has "discovered" the attraction, visiting it for longer reduces their utility. City centers, particularly old parts of the city, can be a "secondary-cluster" attraction, that is, a group of secondary attractions that, when taken as one, prolong visitor satisfaction, and hence also the time consuming them, and together can become a primary attraction.

This article presents various novelties with regard to previous research. Firstly, survival models are used to analyze the whole visit. These are non-descriptive methods of analysis, and hence contribute by providing more generalizable results than those stemming from more descriptive methods and data ad-hoc methods (such as cluster analysis), which have been more common in previous studies on time and space consumption, with some notable exceptions $[7,8]$. The present research also bundles together the duration of the visit and the intra-destination duration at each attraction. It also distinguishes between attractions with and without an entrance fee. Moreover, there is a test on the effect of the type of visitor and the characteristics of the visit, on time behavior, such as day visitors versus overnight visitors, peak-season visitor versus off-season visitor, informed versus non-informed visitor, highly motivated visitor versus visitor with low motivation. The analysis presented here focuses on the city of Girona (Spain), where the majority of mass tourism attractions are built heritage attractions found in a small area of the city (the old part), within walking distance of each other. Data combines Global Positioning System (GPS) and traditional questionnaires. We use information on determinants of time consumption behavior, which can be quite easy to obtain or generate DMO, and other interested agents: socio-demographic characteristics of the visitor; the tourist group; previous knowledge of the destination and sources of information on the heritage site. The results from this type of analysis contribute to existing information on time consumption, which is still relatively scarce, and can be useful for managing tourists and tourist flows in small crowded spaces, and also to better satisfy tourists' expectations and preferences for heritage sites. Knowledge regarding the time tourists spend visiting the historic area of the city, the attractions they choose to visit, and length of time spent at each attraction provide valuable insights for tourism and city planners and managers. In particular, this article provides information on: (1) how much time tourists spend visiting the historic area; (2) what the main attractions are, based on time spent at the attractions and visitor numbers; (3) what characteristics of the tourist, the visit and the attraction (with and without an entrance fee) affect visitors' time consumption behavior.

This study was carried out in Girona, a medium-sized city and tourist capital of the Costa Brava, a well-known international tourist destination in the north-east of Spain. Girona is located around $100 \mathrm{~km}$ north of Barcelona, and has a population of 97,227 (in 2014), a surface of 39.1 square kilometers and an average non-resident population of 17,839 . Tourism is an important economic activity in Girona; 
in 2013, the city had almost 2000 hotel beds, accounting for around $7.5 \%$ of the gross added value generated by the economic activity of services in the city. The main heritage tourist attraction is the "Barri Vell" (the old part of the city), which has multiple built heritage attractions such as the Cathedral and the Jewish quarter, two of the "must-see" historic sites in Girona.

This article is structured as follows: Section 2 poses the research questions and reviews previous evidence, which determines the factors and variables included in the analysis, and relate to determinants in the heterogeneity of time consumption. This is followed by a description of the data and methods of analysis used. Section 4 presents detailed results of the econometric estimations, which is followed by the discussion and concluding remarks.

\section{Materials and Methods}

The following research questions are addressed in this article: (1) Are there primary attractions in the old part of the city? (in terms of number of visitors and time spent at the attractions); (2) How long do tourists spend visiting the all of the old part? (3) Are there "observable" visitor characteristics and trip characteristics relevant when determining the likelihood of visiting a particular attraction and the time spent at the attraction or all of the old part? The first and second questions are answered using descriptive statistics. In order to answer the third question, a decision on which variables to include in the analysis needs to be made. To this end, the literature review has offered some insights. Literature on time spent on an activity/stop along a route has addressed the issue of first-time versus repeat visits and the visitor having prior knowledge of the destination and its attractions. Those who are new to a destination may spend more time visiting, because they explore the destination more, ensuring they visit the primary attractions [7,12]. However, Grinberger et al. [8] found that previous knowledge of the destination (from previous experience or from information) did not seem to have any influence on the behavior of the various clusters of tourists identified. In the present analysis, first time vs. repeat visitors are included as a determinant variable of time consumption. In fact, the only previous evidence for the case of Girona is a study by Galí and Donaire [13], which found that socio-demographic variables did not appear to influence how visitors were assigned to clusters, but the "characteristics of the visit" (e.g., the degree of information known, guided visit, the number of companions in the group, etc.) did seem to have an influence.

The present study includes the usual variables used in demand analysis of tourist socio-demographics. These include age, gender and level of studies. In this study, we have added the variable "traveling with children" as this can affect preferences, and hence tourists' decision-making [10,14]. However, Kemperman et al. [15] and Tchetchick et al. [7] found that the number of children in the travel party was not a significant factor. Nationality is also a common determinant in tourism demand studies. Nationality can be a proxy for cultural proximity $[16,17]$ and this in turn can generate longer visits and are more likely to visit a specific attraction. Grimberger et al. [8] also included information in their cluster analysis of visitors (visiting with a guidebook; better informed visitors may be expected to visit more attractions and spend longer visiting them). However, they found that this was not a relevant determinant of space-temporal heterogeneity. Finally, three more potentially determinant factors are included. First, a time-constraint variable: day visitors vs. those staying overnight in the city. Since day-visitors have less time to visit the city, they are expected to spend less time visiting it. Seasonal visits are also included. In the peak season, visits are shorter due to overcrowding. According to demand analysis, a high rating and no admission fee (price is zero) increase demand. Therefore, in this study, the probability of visiting an attraction and the length of the visit is expected to increase.

The data used in the study comes from two information-gathering instruments [7]. High-resolution time-space data was collected by global positioning system (GPS); and the other relevant information was collected by traditional questionnaires. GPS in particular has been used previously in historic sites and cities $[7,18]$. GPS can accurately track a visitor's position each second, and provide information on visitor behavior, total time of the visit and time at each site/attraction. GPS data has proved to be much more accurate and unbiased than direct observation methods $[7,13]$. Tracking provided data on the 
time the tourist spent at each attraction and on the whole visit. Data on visitors' socio-demographics and trip characteristics was obtained from a questionnaire given to tracked visitors after their visit.

During 2013 (from 1 February to 31 December), the majority of GPS location kits were given to tourists at the Girona tourist office daily, previous to their visit to the old town. A small percentage of GSP were distributed to official guides who accompanied organized group visits. Other GPS were carried by researchers who then followed those tourists who were visiting by themselves, and had not entered the tourist office, which is located at one of the main entrances to the old part. A GPS kit was given to individuals (only one if there were two or more people in a group), and in the case of a guided-visit, to the guide. When the tourist returned the GPS to the tourist office, they were given the questionnaire to fill out. One adult member in the tourist group answered the questions. The questions were on the tourist socio-demographics as well as on trip and visit characteristics. The GPS was the QStarz Data Logger (BT-Q1000XT/TR-Q1000XT) model. It registered the position of the visitor every two seconds, measuring the latitude and longitude coordinates, with a precision of a few meters and in real time. Data were automatically saved in the location kits and downloaded to a PC (software QTravel) when the visitor returned the GPS. Each GPS had autonomy of $72 \mathrm{~h}$; they were charged in the tourist office when not in use. The final number of valid tracks and associated questionnaires was 1363. The sample was created so that the error was $3 \%$, with $95 \%$ confidence and maximum variability $(p=q=0.5)$.

Information was analyzed using different econometric models. First, for the case of the determinants of the time consumed on the whole visit to the old part, a duration model was used (see for example Martinez-Garcia and Raya [19] and Peypoch et al. [20]). Thrane [21] has several concerns about duration models in tourism. The main concern is that for a great many of the trips tourists make, the arrival and departure dates (and, therefore, the length of time at the destination) has been decided in advance. This is not our case since we are estimating the length of a visit to a specific location at the destination: the old part of a destination city (and its attractions). Duration models (or survival or hazard models) use specific distribution functions for the duration variable, and takes into account the positive nature of that variable, allowing any duration to be considered. These models estimate the time spent in a given state before transition to another state [22], also known as "spell", and models either the duration (the length of time the tourist spends on the whole visit to the historic site in the city) or the likelihood of transition (ending the visit), conditioned to survival up to time " $t$ ". They are also used to estimate whether duration correlates with the explanatory variables of the observed duration (the regressors or covariates of the model). The chosen model is the log-logistic distribution function for duration. Appendix A outlines the technical reason for this choice.

For the case of the visit to each resource/attraction in the old part of the city, the first analysis applied a multivariate probit model to find out the probability of visiting one particular attraction. After that, the analysis of the time spent at each attraction and the factors that influence it will provide the basis for further segmentation of the market. Along the same lines as Tchetchick et al. [7], a simultaneous Tobit model was estimated, and it is considered that the decision regarding the length of time to spend at each attraction is simultaneous to the decision taken on visiting a particular attraction, and the data are truncated (not all visitors visited all the attractions).

\section{Results}

Descriptive statistics of the variables employed in the analysis are presented in Table 1. Motivation for the trip was not used as an explanatory variable, as nearly all visitors in the sample responded "holiday" purposes. Most visitors do not stay in the city of Girona overnight, hence are day-visitors; around a quarter $(24.2 \%)$ are Catalan and $27.3 \%$ come from other parts of Spain. Most visitors have university studies (graduate and postgraduate), for the majority it is their first time in Girona (72\%), they visit without children, they are independent visitors (no guided tour) and do the tour without a guidebook. Visitors are distributed almost equally among peak-season and off-season periods. The average visitor spent almost an hour (59.28 min with a standard deviation of $66.10 \mathrm{~min}$ ) visiting 
the historic site and $9.41 \mathrm{~min}$ at each attraction. For the analysis, the length of the visit was restricted to 3 hours and length of time at an attraction to $90 \mathrm{~min}$.

Table 1. Descriptive statistics.

\begin{tabular}{cccccc}
\hline Variables & Mean & Std. Dev. & Variables Mean Std. Dev. & \\
\hline Staying in Girona & 0.267 & 0.442 & Catalan & 0.242 & 0.428 \\
Postgraduate studies & 0.274 & 0.446 & Other Spanish & 0.273 & 0.446 \\
Graduate studies & 0.446 & 0.497 & France & 0.133 & 0.340 \\
Secondary school studies & 0.240 & 0.427 & UK & 0.056 & 0.231 \\
Primary school studies & 0.040 & 0.196 & Germany & 0.037 & 0.188 \\
First time in Girona & 0.720 & 0.449 & North America & 0.039 & 0.193 \\
Visiting alone & 0.105 & 0.307 & Holland and Belgium & 0.047 & 0.211 \\
Visiting with partner/spouse & 0.637 & 0.481 & South America & 0.073 & 0.260 \\
Visiting with a group & 0.258 & 0.437 & European Nordic countries & 0.017 & 0.129 \\
Children & 0.175 & 0.380 & European Eastern countries & 0.026 & 0.159 \\
Guided tour & 0.092 & 0.290 & Italy & 0.267 & 0.442 \\
Guidebook & 0.271 & 0.445 & Other & 0.274 & 0.446 \\
Peak season & 0.483 & 0.500 & Minutes at attraction & 9.41 & 13.23 \\
Observations & 970 & 970 & Time at sight & 59.86 & 37.18 \\
\hline
\end{tabular}

Table 2 presents the proportion of visitors and average time spent at each attraction. The most visited were the Cathedral (66.40\% of visitors), the Archaeological Promenade (64.78\%) (open-air), the City Walls (77.87\%) (open air), and Saint Felix Church (47.74\%). The least visited were the Art Gallery and Saint Peter's Church, which accounted for less than a quarter of the visitors. In general, attractions without an admission charge $(48.57 \%)$ were more visited than those with an admission charge $(27.77 \%)$. However, the time spent at each attraction was higher when the visitor had to pay to visit it. That is the case with the Jewish Museum (14.71\%), Saint Felix Church and Saint Peter's Church $(13.50 \%)$, the two attractions where the visitor spent most time. On average, more time was spent (11.11 $\mathrm{min}$ ) in the case of the attractions which charge for admission.

Table 2. Proportion of visitors and time spent, by attraction.

\begin{tabular}{ccc}
\hline Attraction & Minutes & \% of Visits \\
\hline Arab Baths & 6.01 & 38.22 \\
Cathedral & 9.87 & 66.40 \\
Jewish Museum (Centre Bonastruch sa Porta) & 14.71 & 36.65 \\
Saint Felix Church & 13.94 & 47.74 \\
French Gardens (jardins de la francesa) & 3.69 & 30.03 \\
City Walls (muralles) & 9.25 & 77.87 \\
Art Gallery & 5.24 & 20.10 \\
Archeological Promenade (Promenade Archeologic) & 7.09 & 64.74 \\
Agullana Palace & 10.88 & 24.74 \\
Saint Peter's Church (Sant Pere de Galligans) & 13.70 & 20.37 \\
Admission fee & 11.11 & 27.77 \\
No admission fee & 8.70 & 48.57 \\
\hline
\end{tabular}

\subsection{Length of Total Visit to the Old Part}

Table 3 presents detailed results of the model estimation of the best fitting duration model (the log-logistic model; standard errors have been estimated robustly given that, with attraction-person data, the assumed homoscedasticity is very questionable). A positive sign in the coefficients estimated in the Log-logistic model is interpreted as an increase in survival time (visit duration). The first column in Table 3 in the main text presents the results from the model without any control for the attractions. Given the functional form and the value $\gamma<1(0.38)$, the value of the hazard increases with time up to a specific moment (around $60 \mathrm{~min}$ ), following which it begins to decrease. 
Table 3. Determinants of the whole visit to the old part.

\begin{tabular}{|c|c|c|}
\hline & (1) & (3) \\
\hline Variables & Time Whole Visit & TWV by Episode \\
\hline Staying in Girona & $\begin{array}{l}0.117^{* *} \\
(0.0505)\end{array}$ & $\begin{array}{l}0.160^{* * *} \\
(0.0193)\end{array}$ \\
\hline Graduate studies & $\begin{array}{c}0.0155 \\
(0.0566)\end{array}$ & $\begin{array}{c}-0.0418 \text { * } \\
(0.0216)\end{array}$ \\
\hline Secondary school studies & $\begin{array}{c}-0.171^{* * *} \\
(0.0618)\end{array}$ & $\begin{array}{c}-0.134^{* * *} \\
(0.0241)\end{array}$ \\
\hline Primary school studies & $\begin{array}{c}-0.0738 \\
(0.104)\end{array}$ & $\begin{array}{l}-0.0382 \\
(0.0410)\end{array}$ \\
\hline First time in Girona & $\begin{array}{c}0.0689 \\
(0.0526)\end{array}$ & $\begin{array}{c}0.0658^{* * *} \\
(0.0206)\end{array}$ \\
\hline Visiting with partner/spouse & $\begin{array}{c}-0.247^{* * *} \\
(0.0758)\end{array}$ & $\begin{array}{c}-0.192 * * * \\
(0.0284)\end{array}$ \\
\hline Visiting with a group & $\begin{array}{c}-0.269^{* * * *} \\
(0.0833)\end{array}$ & $\begin{array}{c}-0.188^{* * *} \\
(0.0312)\end{array}$ \\
\hline Children & $\begin{array}{l}-0.129 * \\
(0.0718)\end{array}$ & $\begin{array}{c}-0.125^{* * *} \\
(0.0255)\end{array}$ \\
\hline Guided tour & $\begin{array}{l}-0.0487 \\
(0.0773)\end{array}$ & $\begin{array}{c}-0.101 * * * \\
(0.0318)\end{array}$ \\
\hline Guidebook & $\begin{array}{l}0.241^{* * *} \\
(0.0544)\end{array}$ & $\begin{array}{l}0.167^{* * *} \\
(0.0205)\end{array}$ \\
\hline Peak season & $\begin{array}{c}-0.135 * * * \\
(0.0452)\end{array}$ & $\begin{array}{c}-0.0605^{* * *} \\
(0.0172)\end{array}$ \\
\hline Other parts of Spain & $\begin{array}{c}-0.143^{* *} \\
(0.0597)\end{array}$ & $\begin{array}{c}-0.143 \text { *** } \\
(0.0234)\end{array}$ \\
\hline France & $\begin{array}{l}-0.165^{*} \\
(0.0985)\end{array}$ & $\begin{array}{c}-0.249^{* * *} \\
(0.0356)\end{array}$ \\
\hline UK & $\begin{array}{c}-0.491 * * * \\
(0.116)\end{array}$ & $\begin{array}{c}-0.404^{* * *} \\
(0.0424)\end{array}$ \\
\hline Germany & $\begin{array}{c}-0.301 \text { *** } \\
(0.112)\end{array}$ & $\begin{array}{c}-0.187^{* * *} \\
(0.0414)\end{array}$ \\
\hline North America & $\begin{array}{c}-0.320^{* *} \\
(0.125)\end{array}$ & $\begin{array}{c}-0.289^{* * *} \\
(0.0515)\end{array}$ \\
\hline Holland and Belgium & $\begin{array}{c}-0.352 * * * \\
(0.122)\end{array}$ & $\begin{array}{c}-0.297^{* * *} \\
(0.0429)\end{array}$ \\
\hline South America & $\begin{array}{l}-0.0992 \\
(0.0915)\end{array}$ & $\begin{array}{c}-0.0871 \text { ** } \\
(0.0344)\end{array}$ \\
\hline Nordic Countries & $\begin{array}{l}-0.317 \\
(0.268)\end{array}$ & $\begin{array}{c}-0.340^{* * *} \\
(0.101)\end{array}$ \\
\hline Eastern European countries & $\begin{array}{c}-0.331 \text { ** } \\
(0.153)\end{array}$ & $\begin{array}{c}-0.388^{* * * *} \\
(0.0597)\end{array}$ \\
\hline Italy & $\begin{array}{c}-0.0722 \\
(0.113)\end{array}$ & $\begin{array}{l}-0.0497 \\
(0.0495)\end{array}$ \\
\hline Other countries & $\begin{array}{c}-0.370 \text { **** } \\
(0.133)\end{array}$ & $\begin{array}{c}-0.333^{* * *} \\
(0.0512)\end{array}$ \\
\hline Cathedral & & $\begin{array}{c}-0.0895 \text { ** } \\
(0.0374)\end{array}$ \\
\hline Jewish Museum & & $\begin{array}{c}-0.00768 \\
(0.0436)\end{array}$ \\
\hline Lioness's Bottom & & $\begin{array}{l}0.247^{* * * *} \\
(0.0829)\end{array}$ \\
\hline Saint Felix Church & & $\begin{array}{l}0.00554 \\
(0.0395)\end{array}$ \\
\hline French Gardens & & $\begin{array}{l}-0.0648 \\
(0.0458)\end{array}$ \\
\hline City Walls & & $\begin{array}{l}-0.0157 \\
(0.0326)\end{array}$ \\
\hline
\end{tabular}


Table 3. Cont.

\begin{tabular}{ccc}
\hline & $\mathbf{( 1 )}$ & $\mathbf{( 3 )}$ \\
\hline Variables & Time Whole Visit & TWV by Episode \\
\hline Art Gallery & & -0.0131 \\
& & $(0.0495)$ \\
City's History Museum & $0.238^{* * *}$ \\
Archeological Promenade & $(0.0785)$ \\
& & $0.0942^{* *}$ \\
Agullana Palace & & $(0.0370)$ \\
Saint Peter's Church & -0.0249 \\
& & $(0.0484)$ \\
Constant & $4.280^{* * *}$ & 0.0670 \\
& $(0.0877)$ & $(0.0499)$ \\
Observations & 970 & $4.262^{* * *}$ \\
& $* * * p<0.01^{* *} p<0.05, * 0<0.1$. & \\
\end{tabular}

The estimated model profiles the visitor who spends more time visiting as being Catalan, staying in Girona, travelling alone, without children, with a level of studies other than Secondary, who visits in the off-season and with a guidebook in hand. In the second column results shown are controlling for the monument visited. With this additional information, the previous profile can be complemented with the following: he/she is a first-time visitor, does the visit by him/herself (no guided tour) and visits the Art Gallery. With respect to nationalities and attractions, those from UK and the East of Europe visiting the Archaeological Promenade and the Cathedral stay less time at the site.

\subsection{Determinants of the Probability of Visiting a Specific Attraction}

A first-level of decision making for the visitor is whether to visit a specific attraction or not. Tables 4 and 5 present the results of the probit model in which the binary dependent variable (Visited), received the value 1 ; when the visitors decided to visited the attraction $\mathrm{j}$; and 0 when they decided otherwise. Table 4 show the results for attractions with an admission charge, while Table 5 shows the results for attractions with no admission charge. The overall pattern for the explanatory variables is replicated in this model and the dummy variable appears significant in reducing the probability of visiting a specific attraction. The coefficients from the probit model are difficult to interpret because they measure the change in the latent, unobservable dependent variable associated with a change in one of the explanatory variables. Only direct interpretation in terms of sign is possible. Marginal effects are available upon request. Visiting with a guidebook increased the probability of visiting six out of ten attractions. This included all the attractions with an admission charge, as well as the Cathedral and the City Walls. For four of the ten attractions, we have sufficient observations of the visitor's rating of the attraction and it has been included in the analysis. For the two attractions with an admission charge, a higher valuation increased the probability of visiting this attraction. Visiting with children negatively affects the probability of visiting four attractions (two of them with no charge and two with an admission charge). Staying in Girona increased the probability of visiting two attractions (one free of charge and one with an admission charge), while doing a guided tour increases the probability of visiting one attraction with an admission fee (the Jewish Museum) and decreases the probability of visiting the admission free City Walls. It is highly probable that a first-time visitor will visit the City Walls, and that an off-season visitor will visit Agullana Palace. Having a higher education level increases the probability of visiting the Cathedral. In terms of nationalities, and taking a Catalan visitor as the reference category, all other nationalities (except Germans and Italians) have a significantly lower probability of visiting attractions. In most cases, the countries of origin which lower the probability of visiting an attraction are UK, Northern and Eastern European countries. 
Table 4. Probit estimates. Attractions with admission charge.

\begin{tabular}{|c|c|c|c|c|c|}
\hline Variables & Arab Baths & $\begin{array}{l}\text { St. Peter's } \\
\text { Church }\end{array}$ & $\begin{array}{l}\text { Jewish } \\
\text { Museum }\end{array}$ & $\begin{array}{l}\text { St. Felix } \\
\text { Church }\end{array}$ & Art Gallery \\
\hline \multirow[t]{2}{*}{ Staying in Girona } & 0.161 & 3.387 & 1.053 & -1.161 & $3.153 * * *$ \\
\hline & (0.547) & $(2.350)$ & (2.094) & (1.583) & (1.138) \\
\hline \multirow[t]{2}{*}{ Graduate studies } & -0.290 & -3.563 & 3.118 & -0.135 & -0.0277 \\
\hline & $(0.608)$ & $(2.476)$ & $(2.192)$ & $(1.589)$ & $(1.185)$ \\
\hline \multirow[t]{2}{*}{ Secondary school studies } & -0.827 & $-5.207 *$ & -1.104 & 0.405 & -0.885 \\
\hline & $(0.648)$ & $(2.913)$ & $(2.390)$ & $(1.885)$ & $(1.357)$ \\
\hline \multirow[t]{2}{*}{ Primary school studies } & -0.458 & -2.981 & -7.047 & 2.721 & 2.390 \\
\hline & $(1.223)$ & $(4.667)$ & $(4.525)$ & (3.955) & $(2.436)$ \\
\hline \multirow[t]{2}{*}{ First time in Girona } & -0.380 & -2.073 & -2.243 & -1.296 & -0.278 \\
\hline & $(0.561)$ & $(2.283)$ & $(2.042)$ & $(1.703)$ & $(1.152)$ \\
\hline \multirow[t]{2}{*}{ Visiting with partner/spouse } & 0.346 & $-7.243^{* *}$ & 1.995 & -1.715 & $-2.730 *$ \\
\hline & $(0.826)$ & $(3.561)$ & $(3.154)$ & $(2.185)$ & $(1.597)$ \\
\hline \multirow[t]{2}{*}{ Visiting with a group } & 1.119 & -6.356 & 0.974 & -1.507 & -2.652 \\
\hline & $(0.893)$ & $(3.908)$ & (3.307) & $(2.468)$ & $(1.717)$ \\
\hline \multirow[t]{2}{*}{ Children } & -0.690 & $-9.321 * * *$ & 0.165 & $-5.083^{* * *}$ & 0.746 \\
\hline & $(0.642)$ & $(3.039)$ & $(2.362)$ & $(1.835)$ & $(1.419)$ \\
\hline \multirow[t]{2}{*}{ Guided tour } & 0.779 & 3.051 & $5.714^{* *}$ & -1.042 & -2.754 \\
\hline & $(0.901)$ & $(3.371)$ & $(2.845)$ & $(2.537)$ & $(1.855)$ \\
\hline \multirow[t]{2}{*}{ Guidebook } & $0.966^{*}$ & $4.523 *$ & $3.513 *$ & $2.807^{*}$ & $1.836^{*}$ \\
\hline & $(0.541)$ & $(2.409)$ & $(1.997)$ & $(1.590)$ & $(1.091)$ \\
\hline \multirow[t]{2}{*}{ Peak season } & -0.193 & 0.246 & -1.439 & 1.835 & 0.967 \\
\hline & $(0.476)$ & $(2.060)$ & $(1.722)$ & $(1.351)$ & $(0.951)$ \\
\hline \multirow[t]{2}{*}{ Other parts of Spain } & 0.264 & -2.227 & $-5.679 * *$ & $5.916^{* * *}$ & -1.778 \\
\hline & $(0.658)$ & $(2.754)$ & $(2.517)$ & $(1.954)$ & $(1.378)$ \\
\hline \multirow[t]{2}{*}{ France } & -0.701 & -3.919 & $-10.25^{* * *}$ & 2.239 & -1.191 \\
\hline & $(0.833)$ & $(3.624)$ & $(3.019)$ & $(2.768)$ & $(1.673)$ \\
\hline \multirow[t]{2}{*}{ UK } & $-2.767^{* *}$ & $-25.27^{* * *}$ & $-17.22 * * *$ & 0.173 & -2.116 \\
\hline & $(1.139)$ & $(7.039)$ & $(5.143)$ & (3.431) & $(2.663)$ \\
\hline \multirow[t]{2}{*}{ Germany } & 0.753 & -5.187 & $-14.15^{* * *}$ & 2.842 & -1.171 \\
\hline & $(1.276)$ & $(5.277)$ & $(4.464)$ & (3.721) & $(2.210)$ \\
\hline \multirow[t]{2}{*}{ North America } & -0.0871 & $-13.28^{* *}$ & -3.564 & -3.885 & $-5.065^{*}$ \\
\hline & $(1.512)$ & $(6.005)$ & $(5.451)$ & (3.879) & $(2.729)$ \\
\hline \multirow[t]{2}{*}{ Holland and Belgium } & -1.542 & -1.758 & $-15.70^{* * *}$ & -2.851 & $-5.552 * *$ \\
\hline & $(1.425)$ & $(5.418)$ & $(4.545)$ & $(3.622)$ & $(2.786)$ \\
\hline \multirow[t]{2}{*}{ South America } & -1.011 & $-9.629 * *$ & -4.211 & 3.382 & -1.427 \\
\hline & $(1.131)$ & $(4.425)$ & $(4.136)$ & $(2.925)$ & $(2.332)$ \\
\hline \multirow[t]{2}{*}{ Nordic countries } & -3.270 & $-15.34 *$ & $-25.56^{* * *}$ & $-8.245 *$ & $-7.626^{*}$ \\
\hline & $(2.174)$ & $(8.338)$ & $(7.146)$ & $(4.638)$ & $(4.599)$ \\
\hline \multirow[t]{2}{*}{ Eastern European countries } & $-4.237^{* *}$ & $-16.83^{* *}$ & $-10.60 *$ & 0.720 & $-7.210 *$ \\
\hline & $(1.906)$ & (7.799) & $(5.817)$ & $(4.494)$ & $(3.348)$ \\
\hline \multirow[t]{2}{*}{ Italy } & 1.554 & -6.050 & 7.177 & 8.909 & -0.687 \\
\hline & $(1.401)$ & $(7.279)$ & $(6.429)$ & $(6.326)$ & $(2.749)$ \\
\hline Other countries & $-4.274^{* * *}$ & $-18.98^{* * *}$ & -8.253 & -2.050 & $-7.434^{* *}$ \\
\hline & $(1.495)$ & $(6.402)$ & $(5.696)$ & $(2.990)$ & $(3.034)$ \\
\hline Rating of attraction & $1.632^{* * *}$ & $2.366^{* * * *}$ & & & \\
\hline & $(0.0963)$ & $(0.605)$ & & & \\
\hline Constant & $-8.017^{* * *}$ & $-21.62 * * *$ & $-6.772 *$ & -3.162 & $-8.280 * * *$ \\
\hline & $(1.244)$ & $(5.706)$ & $(3.975)$ & $(2.847)$ & $(2.283)$ \\
\hline Observations & 1363 & 1360 & 1345 & 1351 & 1363 \\
\hline
\end{tabular}

Robust standard errors in parentheses. ${ }^{* * *} p<0.01,{ }^{* *} p<0.05,{ }^{*} p<0.1$. 
Table 5. Probit estimates. Attractions with no admission charge.

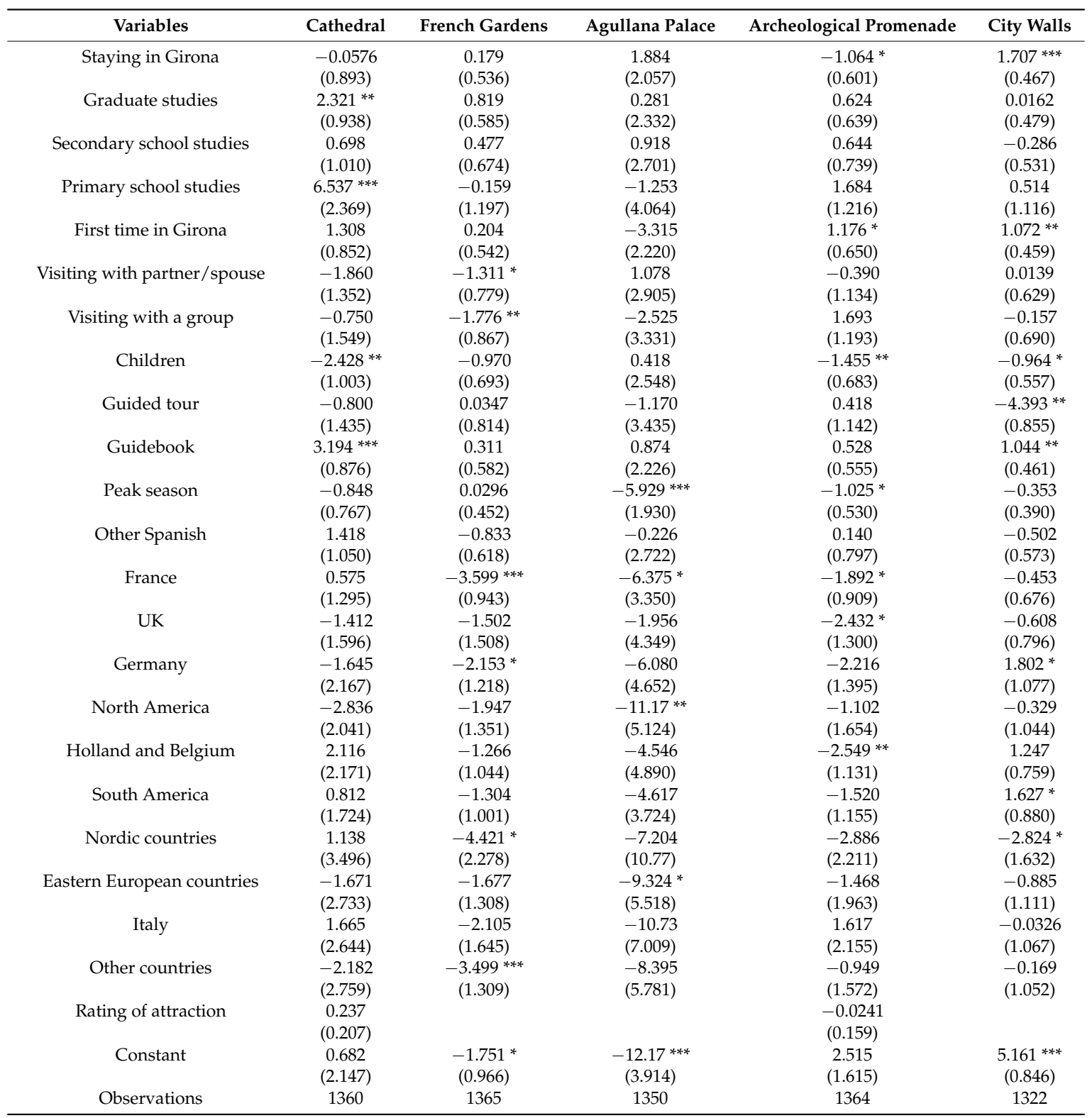

Robust standard errors in parentheses. ${ }^{* *} p<0.01,{ }^{* *} p<0.05,{ }^{*} p<0.1$.

\subsection{Determinants of the Time Spent at a Specific Attraction.}

A second-level of decision making for the visitor is the time spent visiting a specific attraction. An analysis of the determinants of this decision shows us the specific characteristics of the visitor who stays longer at a given attraction, indicating a deeper level of experience. As in Tchetchick et al. (2009), we understand this decision is simultaneous to the decision to visit, or not visit, a specific attraction. Moreover, the data is truncated (not all the visitors visit all the attractions). Tables 6 and 7 show the results of the simultaneous Tobit model, in which the dependent variable is the time elapsed between starting and ending the visit to the attraction. A higher rating implies a longer time spent at the attraction (with the exception of the Archaeological Promenade). In four attractions, visiting with children reduces the time spent at the attraction, while in five attractions, using a guidebook increases the time spent. Other variables have different effects depending on the attraction. For example, being accommodated in Girona increases the time spent in the Art Gallery but reduces the time spent at Saint Felix Church. Similarly, a guided tour reduces the time spent at the City Walls or the Art Gallery and 
increases the time spent at the Jewish Museum. In peak season visitors spend more time at Saint Felix Church and less in Agullana Palace and the Archaeological Promenade. Finally, if this is a first time visit to Girona, the time spent at the City Walls and the Archaeological Promenade is higher, while that spent at Agullana Palace is lower. Regarding nationalities, and interpreting the effects of Catalan visitors, the following was found: being from the UK reduces the time spent at five attractions; being from Holland and Belgium reduces it at four; from France and North America and Northern European countries, at three; being from Latin America reduces the time spent at two specific attractions and being a German visitor reduces the time spent at one attraction (the Jewish Museum). The City Walls is the only attraction where people from Italy, Germany, Holland and Belgium spend more time than the Catalan visitors.

Table 6. Tobit estimates. Attractions with admission charge.

\begin{tabular}{|c|c|c|c|c|c|}
\hline Variables & Arab Baths & St. Peter's Church & Jewish Museum & St. Felix Church & Art Gallery \\
\hline \multirow{2}{*}{ Staying in Girona } & -0.0289 & 0.103 & -0.0390 & $-0.170 * *$ & $0.179^{* *}$ \\
\hline & $(0.0896)$ & $(0.0909)$ & $(0.0819)$ & $(0.0801)$ & $(0.0880)$ \\
\hline \multirow[t]{2}{*}{ Graduate studies } & -0.0613 & -0.0778 & 0.0883 & -0.0298 & 0.0508 \\
\hline & $(0.0961)$ & $(0.0976)$ & $(0.0876)$ & $(0.0852)$ & $(0.0971)$ \\
\hline \multirow[t]{2}{*}{ Secondary school studies } & -0.0502 & -0.147 & -0.00835 & 0.00916 & 0.00162 \\
\hline & $(0.110)$ & $(0.116)$ & $(0.103)$ & $(0.100)$ & $(0.113)$ \\
\hline \multirow[t]{2}{*}{ Primary school studies } & -0.0166 & -0.0226 & -0.232 & 0.0845 & 0.254 \\
\hline & $(0.215)$ & $(0.202)$ & $(0.202)$ & $(0.189)$ & $(0.206)$ \\
\hline \multirow[t]{2}{*}{ First time in Girona } & -0.0293 & -0.157 & -0.106 & -0.0190 & -0.00423 \\
\hline & $(0.0957)$ & $(0.0954)$ & $(0.0868)$ & $(0.0846)$ & $(0.0957)$ \\
\hline \multirow[t]{2}{*}{ Visiting with partner/spouse } & -0.0273 & -0.200 & 0.0593 & -0.0567 & -0.191 \\
\hline & $(0.135)$ & $(0.132)$ & $(0.122)$ & $(0.119)$ & $(0.130)$ \\
\hline \multirow[t]{2}{*}{ Visiting with a group } & 0.115 & -0.155 & 0.0850 & -0.0817 & -0.179 \\
\hline & $(0.148)$ & $(0.146)$ & $(0.136)$ & $(0.132)$ & $(0.143)$ \\
\hline \multirow[t]{2}{*}{ Children } & -0.113 & $-0.326^{* * *}$ & 0.000964 & -0.155 & -0.0310 \\
\hline & $(0.105)$ & $(0.118)$ & $(0.0989)$ & $(0.0959)$ & $(0.108)$ \\
\hline \multirow[t]{2}{*}{ Guided tour } & 0.0990 & 0.164 & $0.249 *$ & -0.0856 & -0.259 * \\
\hline & $(0.151)$ & $(0.142)$ & $(0.128)$ & $(0.127)$ & $(0.152)$ \\
\hline \multirow[t]{2}{*}{ Guidebook } & 0.154 * & 0.150 & $0.190 * *$ & 0.0722 & $0.200^{* *}$ \\
\hline & $(0.0919)$ & $(0.0949)$ & $(0.0848)$ & $(0.0825)$ & $(0.0919)$ \\
\hline \multirow[t]{2}{*}{ Peak season } & -0.0180 & -0.0320 & -0.000778 & $0.185^{* * *}$ & 0.0334 \\
\hline & $(0.0788)$ & $(0.0810)$ & $(0.0723)$ & $(0.0703)$ & $(0.0805)$ \\
\hline \multirow[t]{2}{*}{ Other parts of Spain } & 0.0448 & -0.102 & $-0.232 * *$ & $0.307^{* * *}$ & -0.0966 \\
\hline & $(0.114)$ & $(0.114)$ & $(0.105)$ & $(0.103)$ & $(0.115)$ \\
\hline \multirow[t]{2}{*}{ France } & -0.0861 & -0.190 & $-0.391^{* * *}$ & 0.0174 & -0.0602 \\
\hline & $(0.142)$ & $(0.144)$ & $(0.132)$ & $(0.128)$ & $(0.143)$ \\
\hline \multirow[t]{2}{*}{ UK } & -0.326 * & $-1.044^{* * *}$ & $-0.822 * * *$ & -0.0410 & -0.262 \\
\hline & $(0.193)$ & $(0.255)$ & $(0.185)$ & $(0.168)$ & $(0.193)$ \\
\hline \multirow[t]{2}{*}{ Germany } & 0.175 & -0.109 & $-0.465^{* *}$ & 0.220 & 0.0298 \\
\hline & $(0.226)$ & $(0.226)$ & $(0.206)$ & $(0.198)$ & $(0.214)$ \\
\hline \multirow[t]{2}{*}{ North America } & -0.0786 & $-0.470^{* *}$ & -0.322 & -0.183 & -0.344 \\
\hline & $(0.239)$ & $(0.239)$ & $(0.200)$ & $(0.199)$ & $(0.239)$ \\
\hline \multirow[t]{2}{*}{ Holland and Belgium } & $-0.420^{* *}$ & -0.130 & $-0.594^{* * *}$ & -0.120 & $-0.453^{* *}$ \\
\hline & $(0.200)$ & $(0.205)$ & $(0.192)$ & $(0.181)$ & $(0.222)$ \\
\hline \multirow[t]{2}{*}{ South America } & -0.166 & $-0.392^{* *}$ & -0.240 & 0.213 & -0.149 \\
\hline & $(0.174)$ & $(0.174)$ & $(0.159)$ & $(0.156)$ & $(0.177)$ \\
\hline \multirow[t]{2}{*}{ Nordic countries } & -0.453 & -0.528 & $-0.941 *$ & -0.182 & -0.581 \\
\hline & $(0.342)$ & $(0.351)$ & $(0.323)$ & $(0.285)$ & $(0.395)$ \\
\hline \multirow[t]{2}{*}{ Eastern European countries } & $-0.643^{* *}$ & $-0.667^{* *}$ & $-0.451 *$ & 0.0758 & $-0.505^{*}$ \\
\hline & $(0.295)$ & $(0.299)$ & $(0.238)$ & $(0.230)$ & $(0.294)$ \\
\hline \multirow[t]{2}{*}{ Italy } & 0.347 & -0.240 & 0.361 & 0.313 & 0.105 \\
\hline & $(0.282)$ & $(0.297)$ & $(0.274)$ & $(0.274)$ & $(0.277)$ \\
\hline Other countries & $-0.652 * * *$ & $-0.682^{* * *}$ & $-0.489^{* *}$ & 0.229 & $-0.597^{* *}$ \\
\hline & $(0.235)$ & $(0.253)$ & $(0.206)$ & $(0.197)$ & $(0.249)$ \\
\hline Rating of attraction & $0.240^{* * *}$ & $0.0944^{* * *}$ & & & \\
\hline & $(0.0130)$ & $(0.0231)$ & & & \\
\hline Constant & $-1.138 * * *$ & $-0.843^{* * *}$ & -0.150 & -0.117 & $-0.672 * * *$ \\
\hline & $(0.180)$ & $(0.220)$ & $(0.155)$ & $(0.151)$ & $(0.165)$ \\
\hline Observations & 1363 & 1360 & 1345 & 1351 & 1363 \\
\hline
\end{tabular}

Robust standard errors in parentheses. ${ }^{* *} p<0.01,{ }^{* *} p<0.05,{ }^{*} p<0.1$. 
Table 7. Tobit estimates. Attractions with no admission charge.

\begin{tabular}{|c|c|c|c|c|c|}
\hline Variables & Cathedral & French Gardens & Agullana Palace & Archeological Promenade & City Walls \\
\hline \multirow[t]{2}{*}{ Staying in Girona } & -0.0289 & 0.00589 & 0.0456 & -0.112 & 0.0133 \\
\hline & $(0.0896)$ & $(0.0829)$ & $(0.0857)$ & $(0.0809)$ & $(0.0664)$ \\
\hline \multirow[t]{2}{*}{ Graduate studies } & -0.0613 & 0.131 & 0.0376 & 0.0786 & 0.120 * \\
\hline & $(0.0961)$ & $(0.0903)$ & $(0.0932)$ & $(0.0868)$ & $(0.0720)$ \\
\hline \multirow[t]{2}{*}{ Secondary school studies } & -0.0502 & 0.0883 & 0.0885 & 0.0505 & 0.0608 \\
\hline & $(0.110)$ & $(0.107)$ & $(0.109)$ & $(0.102)$ & $(0.0837)$ \\
\hline \multirow[t]{2}{*}{ Primary school studies } & -0.0166 & -0.0495 & 0.110 & $0.376^{*}$ & 0.207 \\
\hline & $(0.215)$ & $(0.200)$ & $(0.199)$ & $(0.204)$ & $(0.154)$ \\
\hline \multirow[t]{2}{*}{ First time in Girona } & -0.0293 & 0.0472 & -0.159 * & $0.215^{* *}$ & $0.187^{* * *}$ \\
\hline & $(0.0957)$ & $(0.0902)$ & $(0.0908)$ & $(0.0865)$ & $(0.0699)$ \\
\hline \multirow[t]{2}{*}{ Visiting with partner/spouse } & -0.0273 & -0.134 & 0.0256 & 0.0294 & -0.0310 \\
\hline & $(0.135)$ & $(0.121)$ & $(0.130)$ & $(0.122)$ & $(0.101)$ \\
\hline \multirow[t]{2}{*}{ Visiting with a group } & 0.115 & -0.168 & -0.170 & $0.249^{*}$ & -0.0773 \\
\hline & $(0.148)$ & $(0.135)$ & $(0.144)$ & $(0.135)$ & $(0.111)$ \\
\hline \multirow[t]{2}{*}{ Children } & -0.113 & $-0.227^{* *}$ & -0.0100 & $-0.206^{* *}$ & $-0.215^{* * * *}$ \\
\hline & $(0.105)$ & $(0.105)$ & $(0.105)$ & $(0.0969)$ & $(0.0823)$ \\
\hline \multirow[t]{2}{*}{ Guided tour } & 0.0990 & -0.0534 & -0.0560 & -0.164 & $-0.730^{* * * *}$ \\
\hline & $(0.151)$ & $(0.134)$ & $(0.140)$ & $(0.128)$ & $(0.107)$ \\
\hline \multirow[t]{2}{*}{ Guide book } & $0.154^{*}$ & 0.0169 & 0.0518 & 0.211 ** & $0.189 * * *$ \\
\hline & $(0.0919)$ & $(0.0869)$ & $(0.0902)$ & $(0.0850)$ & $(0.0712)$ \\
\hline \multirow[t]{2}{*}{ Peak season } & -0.0180 & 0.0350 & $-0.217^{* * *}$ & $-0.199^{* * *}$ & -0.0635 \\
\hline & $(0.0788)$ & $(0.0734)$ & $(0.0763)$ & $(0.0722)$ & $(0.0585)$ \\
\hline \multirow[t]{2}{*}{ Other parts of Spain } & 0.0448 & -0.142 & -0.0669 & 0.0342 & 0.0188 \\
\hline & $(0.114)$ & $(0.106)$ & $(0.110)$ & $(0.108)$ & $(0.0837)$ \\
\hline \multirow[t]{2}{*}{ France } & -0.0861 & $-0.588^{* * *}$ & $-0.278^{* *}$ & $-0.256^{*}$ & 0.106 \\
\hline & $(0.142)$ & $(0.143)$ & $(0.140)$ & $(0.131)$ & $(0.109)$ \\
\hline \multirow[t]{2}{*}{ UK } & $-0.326^{*}$ & $-0.485^{* * *}$ & -0.107 & -0.391 ** & 0.116 \\
\hline & $(0.193)$ & $(0.185)$ & $(0.180)$ & $(0.172)$ & $(0.141)$ \\
\hline \multirow[t]{2}{*}{ Germany } & 0.175 & -0.292 & -0.177 & -0.255 & $0.359 * *$ \\
\hline & $(0.226)$ & $(0.212)$ & $(0.216)$ & $(0.201)$ & $(0.173)$ \\
\hline \multirow[t]{2}{*}{ North America } & -0.0786 & $-0.360 *$ & -0.367 & $-0.366^{*}$ & 0.0597 \\
\hline & $(0.239)$ & $(0.207)$ & $(0.233)$ & $(0.201)$ & $(0.162)$ \\
\hline \multirow[t]{2}{*}{ Holland and Belgium } & $-0.420 * *$ & -0.148 & -0.205 & -0.208 & $0.494 * * *$ \\
\hline & $(0.200)$ & $(0.184)$ & $(0.198)$ & $(0.182)$ & $(0.161)$ \\
\hline \multirow[t]{2}{*}{ South America } & -0.166 & -0.256 & -0.133 & -0.174 & $0.220 *$ \\
\hline & $(0.174)$ & $(0.160)$ & $(0.168)$ & $(0.161)$ & $(0.133)$ \\
\hline \multirow[t]{2}{*}{ Nordic countries } & -0.453 & $-0.811^{* *}$ & -0.536 & $-0.485^{*}$ & -0.271 \\
\hline & $(0.342)$ & $(0.343)$ & $(0.342)$ & $(0.286)$ & $(0.229)$ \\
\hline \multirow{2}{*}{ Eastern European countries } & $-0.643^{* *}$ & -0.209 & -0.301 & -0.405 * & 0.0653 \\
\hline & $(0.295)$ & $(0.236)$ & $(0.257)$ & $(0.236)$ & $(0.189)$ \\
\hline \multirow[t]{2}{*}{ Italy } & 0.347 & -0.299 & -0.421 & 0.118 & $0.406^{*}$ \\
\hline & $(0.282)$ & $(0.288)$ & $(0.314)$ & $(0.301)$ & $(0.246)$ \\
\hline Other countries & $-0.652^{* * *}$ & $-0.539 * *$ & $-0.390^{*}$ & $-0.384^{*}$ & 0.0376 \\
\hline & $(0.235)$ & $(0.214)$ & $(0.228)$ & $(0.200)$ & $(0.161)$ \\
\hline Rating & $0.240^{* * *}$ & & & -0.00191 & \\
\hline & $(0.0130)$ & & & $(0.0224)$ & \\
\hline Constant & $-1.138^{* * *}$ & $-0.261 *$ & $-0.374^{* *}$ & $0.345 *$ & $0.585 * * *$ \\
\hline & $(0.180)$ & $(0.156)$ & $(0.161)$ & $(0.198)$ & $(0.129)$ \\
\hline Ohservations & 126 & 120 & 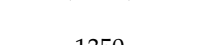 & 1260 & 0.0133 \\
\hline
\end{tabular}

\subsection{Results on the Determinants of Time Demand}

Results show that prior knowledge (being a first-time visitor) generates longer visits (to the whole old part), and also in the Promenade and the City Walls, where the probability of visiting is also higher. It has no effect on other attractions, however. With respect to travelling with children, it is found that the latter reduces the total time of the visit, and also the probability of visiting most attractions, whether free or not, except in some cases (open-air attractions), the Jewish Museum and the Arab Baths, which are non-open-air attractions but are more "exotic" than others like churches and museums. However, once visited, the fact that there are children in the group has a greater effect (reducing time consumption) when attractions are free. As for socio-demographics, it is clear that Catalan visitors spend the most time, and Italians' behavior is similar to Catalans, as opposed to non-Catalan, Spanish visitors. The sense of cultural proximity to Girona's heritage as a determinant of a longer visit [16] appears to be valid for Catalans (and even Italians) but not for visitors from other 
parts from Spain. Visitors other than Catalans and Italians tend to spend less time on the whole visit, and also at each attraction. The main differences concerning a visit to an attraction with a charge are as follows: having to pay reduces the probability of visiting (compared to Catalans) and the time spent visiting is significantly shorter. Concerning information and motivation, in general, tourists visiting with a guidebook spend more time on the whole visit, as well as at each attraction visited, and are more likely to visit any given attraction. Visiting with a guided tour reduces total time of the visit; increases the amount of time at two attractions, the Jewish Museum and the City Walls, and reduces the time at the Art Gallery. Also, a guided tour has no effect on the probability of visiting a given attraction except for the Jewish Museum, in which case it is higher. A possible explanation is that the restriction of the distribution of time among attractions in the guided tour does not satisfy mean visitor's preferences. As for the time constraint, it has been found that those accommodated in Girona spend more on the whole visit, but in general, this has no effect on the time spent at each attraction. Staying in Girona is significant for the Art Gallery: it increases the probability of visiting it and the time spent in it; and the probability of visiting the City Walls (but not the time spent on it). However, it decreases the probability of visiting the Archaeological Promenade and St. Felix Church. Concerning the other "time restrictions", peak season generates shorter duration of the whole visit and of two attractions. As for valuations, results show that high valuations are relevant factors for the probability of visiting an attraction and the time spent in it. Finally, the price constraint also seems to affect the decision to visit; the profile of the time spent by the visitor is, to some extent, different in attractions with and without an entrance fee.

\section{Discussion}

This paper sheds light on knowledge of tourists' time consumption at a heritage area of a city, which is critical to better managing the impact of tourists on cities, and creating a sustainable city tourism destination. The main contribution of this paper is to deepen knowledge of factors affecting the time behavior of tourists when visiting attractions at a destination. This knowledge is useful for managing tourists and tourist flows in small, crowded spaces, and also to better satisfy tourists' expectations and preferences for heritage sites.

We have identified the primary and the secondary attractions, and some key determinants for the likelihood of visiting and the length of time spent at a specific attraction. Previous knowledge of the site has emerged as an important element of time consumption behavior. First-time visitors differ from repeat visitors, mainly in that they spend more time on the visit because they visit more attractions, but only two attractions are more likely to be visited because of this knowledge. Having more information (through guidebooks) increases time consumption and the likelihood of visiting an attraction. Therefore, guidebooks are instrumental for planners when it comes to directing visitor flows to specific sites and specific areas of the city, and to desired specific attractions. Guided tours are also a valuable tool for directing flows and time consumption. Findings show that guided tours tend to reproduce the "common" attraction and time consumption pattern. Guided tours can be organized so as to prioritize specific attractions, and to time the total visit to particular attractions in accordance with the city's wishes. Guided tours can be organized so as to prioritize specific attractions, and to modulate the time of the total visit according to desired city time and place use. Time spent on each attraction can be examined and modified in order to satisfy tourist preferences.

Time constraints are also relevant. Results show that day-visitors (in contrast to those staying over in the city) spend less time on the whole visit, and also visit fewer attractions. Therefore, the consumption of attractions will be significantly different depending on the type of visitors the city receives. Persuading visitors to stay overnight at the destination (city) could increase the revenue for attractions charging admission, since they would receive more visitors. More revenue could also be generated in the off-season. Concerning socio-demographics, nationality has proved to be a relevant factor of time consumption. Catalans (and Italians) are the highest consumers of time. Sites attracting these visitors are occupied for longer by each visitor, and receive a larger number 
of visitors, especially in the case of attractions charging admission. This information is valuable when planning and organizing attractions and visits, and is relevant to generating revenues from visitors. In this sense, domestic tourism is a means of supporting the national tourism industry and consequently regional growth. As Garau [23] points out, government authorities have to create plans and actions. In our case, local tourism authorities and planners can try to attract visitors to secondary attractions and decongest primary attractions, and also focus on domestic and new visitors, offering them more information.

For example, some actions available to local authorities that could help attract visitors to secondary attractions involve opening heritage sites of high artistic or historical value which are not currently open. Cultural itineraries in urban areas are increasingly valued for their fresh perspective, unusual spaces, or attractions based on uniqueness. These spaces add to the depth of places of visit and contribute not only to distributing flows and decongesting saturated spaces but also to offer a more complete and richer vision of the tourist experience. Secondly, the problem with some of the secondary attractions is that they go unnoticed and often fail to attract the attention of the visitor. This is because the interest in primary attractions render them invisible. Actions related to signposting, lighting, and integrating secondary sites in local guided tours and leaflets, in traditional formats and using "smart destinations" formats favored by new technologies [23], would contribute to their value and make them more visible.

Similarly, information management is another tool available to local management, and smart tourism tools can be very useful in this context. The results of the study show the importance of tourist time consumption, and the visitor investing time in finding out information about the destination. Thus, implementing certain actions can be powerful tools for local tourism managers. Examples are publishing detailed leaflets and themed pamphlets, developing mobile phone apps and "a la carte" information systems, and creating complementary information points in urban areas suffering from congestion.

Finally, if results obtained in the case of Girona could be generalized, cities receiving family tourism should take into consideration that children affect the time consumption pattern and the probability of visiting specific attractions, and this effect is generally negative. Offering complementary services for children could be a way of increasing the attractiveness of the heritage area and its attractions; to that end, more information on the age of the children would be needed. The study presented here could be improved in the future by including more variables in the analysis: socio-demographic characteristics of the visitor such as income level and cultural interest; visitor's valuation of attraction's attributes; congestion levels at the attraction; possible waiting times and queues to visit certain attractions; information regarding the weather; security of the area, etc., all of which were unavailable in this study. Also, comparison with other cultural tourism destinations will test the extrapolation of results. Finally, it could be combined with an assessment of visitor satisfaction.

Author Contributions: All authors contributed equally to this work. All authors read and approved the final manuscript.

Acknowledgments: This article constitutes an output from the research projects in grants CSO2011-26634 and CSO2015-70633-P, from the Spanish Government.

Conflicts of Interest: The authors declare no conflict of interest.

\section{Appendix A. Duration Model}

There are various duration models, differentiated by the survival function (or its counterpart, the hazard function) they define, but all of them model a positive survival function which may be increasing or decreasing, monotonic or non-monotonic, continuous or discontinuous; the likelihood of a visitor ending the visit after spending " $t$ " periods depends on " $t$ " [22]. Two types of duration models can be estimated: proportional hazard regression models or accelerated failure time models. The most common proportional hazard regression model is the semi parametric Cox model. In this model, the hazard function is specified from two components: the baseline hazard, which involves time but 
not covariates; and a second component, which involves covariates, but not time. In proportional hazard models, the parameter affecting the covariates can be consistently estimated without specifying the functional form for the baseline hazard (as in proportional hazard models, where the effects parameters multiply the hazard. This does not seem to be the case with our data (the Schoenfeld test of residuals rejects the null hypothesis of proportionality in the hazard function, the value of the statistic being 37.83, which given the 20 degrees of freedom leads to a $p$-value of 0.009). Therefore, we have chosen accelerated failure time models.

In the specific distribution functions giving rise to "accelerated failure time models" (Exponential, Weibull, Log-normal, Log-logistic and Gamma), the logarithm " $t$ " is expressed as a linear function of the explanatory variables and a density function of the errors established according to the specific distribution function. Here a covariate can accelerate or decelerate the time to failure. Consistent parameter estimates are dependent on specification of the correct model, so to choose the appropriate model for the data, misspecification tests are used. Our data show there is sufficient evidence to reject the Weibull model (although there is not enough evidence to reject the lognormal model), as the parameter " $k$ " is between 0.35 and -0.01 , at a $95 \%$ level of confidence. The exponential model is rejected as nested in the Weibull model (a specific case where the parameter of the Weibull distribution function $\alpha=1$ ) as the said parameter is situated between 1.19 and 1.32 , at a $95 \%$ level of confidence). In order to discriminate between unnested models (Lognormal, Gamma and Log-logistic), the logarithm of the likelihood function criterion and the AIC criterion are used. According to these two criteria, the model we have finally chosen from those estimated is the log-logistic distribution function for duration, as this is the one with the highest value for the logarithm of the likelihood function $(-1493.6)$ and a lower value for the AIC criterion (2815.2). The values of the likelihood function and the AIC criterion for the other specifications are as follows: exponential $(-1705.17$; 3458) Gompertz $(-1651.39 ; 3351)$ Weibull $(-1704.89 ; 3458)$ Lognormal $(-1647.34 ; 3343)$ Gamma $(-1494.32 ; 3039)$, and for the semi-parametric Cox regression model: $(-7481.81 ; 14,950)$. Chosen model specification is one of the most frequently used in duration studies with accelerated failure models. The non-monotonic log-logistic distribution function is also coherent with the risk function for the dependent variable (length of visit) for our data in the Kaplan-Meier estimation.

Although subject to a specific functional form, the log-logistic distribution function for duration can be used to measure the extent to which the aforementioned conditioned likelihood depends on " $t$ ". The hazard function $(h(t))$ representing the conditional probability of ending the visit at the moment " $t$ " conditioned to having already spent " $t$ " periods is:

$$
h(t)=\frac{\lambda^{1 / \gamma_{t}((1-\gamma) / \gamma)}}{\gamma\left(1+(\lambda t)^{1 / \gamma}\right)}
$$

The effect that " $t$ " has on the hazard function is non-monotonic, increasing first with " $t$ " and then decreasing monotonically if $\gamma<1$. It will be monotonically decreasing if $\gamma<1$.

\section{References}

1. Paci, R.; Marrocu, E. Tourism and regional growth in Europe. Pap. Reg. Sci. 2014, 93, S25-S50. [CrossRef]

2. García-Hernández, M.; de la Calle-Vaquero, M.; Yubero, C. Cultural heritage and urban tourism: Historic city centres under pressure. Sustainability 2017, 9, 1346. [CrossRef]

3. Popp, M. Positive and negative urban tourist crowding: Florence, Italy. Tour. Geogr. 2012, 14, 50-72. [CrossRef]

4. Zhu, H.; Liu, J.; Wei, Z.; Li, W.; Wang, L. Residents' attitudes towards sustainable tourism development in a historical-cultural village: Influence of perceived impacts, sense of place and tourism development potential. Sustainability 2017, 9, 61. [CrossRef]

5. Edwards, D.; Griffin, T. Understanding tourists'spatial behaviour: GPS tracking as an aid to sustainable destination management. J. Sustain. Tour. 2013, 21, 580-595. [CrossRef]

6. UNEP; UNWTO. Making Tourism More Sustainable—A Guide for Policy Makers; UNEP: Nairobi, Kenya; UNWTO: Madrid, Spain, 2005. 
7. Tchetchik, A.; Fleisher, A.; Shoval, N. Segmentation of visitors to a heritage site using high-resolution time-space data. J. Travel Res. 2009, 48, 216-229. [CrossRef]

8. Grinberger, A.Y.; Shoval, N.; McKercher, B. Typologies of tourists' time-space consumption: A new approach using GPS data and GIS tools. Tour. Geogr. 2014, 16, 105-123. [CrossRef]

9. Huang, X.T.; Wu, B.H. Intra-attraction tourist spatial-temporal behavior patterns. Tour. Geogr. 2012, 14, 625-645.

10. Thorton, P.; Shaw, G.; Williams, A. Tourist group holiday decision making and behaviour: The influence of children. Tour. Manag. 1997, 18, 287-297. [CrossRef]

11. Botti, L.; Nicolas Peypoch, N.; Solonandrasana, B. Time and tourism attraction. Tour. Manag. 2008, 29, 594-596. [CrossRef]

12. McKercher, B.; Shoval, N.; Ng, E.; Birenboim, A. First and repeat visitor behaviour: GPS tracking and GIS analysis in Hong Kong. Tour. Geogr. 2011, 14, 147-161. [CrossRef]

13. Galí, N.; Donaire, J.A. Visitors' behavior in heritage cities: The case of Girona. J. Travel Res. 2006, 44, 442-448.

14. Decrop, A. Group processes in vacation decision-making. J. Travel Tour. Mark. 2005, 18, 23-36. [CrossRef]

15. Kemperman, A.; Borgers, A.; Oppewal, H.H. Timmermans Predicting the duration of the theme park visitor's activities: An ordered logit model using conjoint choice data. J. Travel Res. 2003, 41, 375-384. [CrossRef]

16. Morrison, M.; Dowell, D.J. Sense of place and willingness to pay: Complementary concepts when evaluating contributions of cultural resources to regional communities. Reg. Stud. 2015, 49, 1374-1386. [CrossRef]

17. Vu, H.Q.; Li, G.; Law, R.; Ye, B.H. Exploring the travel behaviors of inbound tourists to Hong Kong using geotagged photos. Tour. Manag. 2015, 46, 222-232. [CrossRef]

18. Van Der Spek, S.C. Tracking tourists in historic city centres. In Proceedings of the International Conference on Information and Communication Technologies in Tourism 2010 (ENTER 2010), Lugano, Switzerland, 10-12 February 2010; Gretzel, U., Law, R., Fuchs, M., Eds.; Springer-Verlag: Vienna, Austria, 2010; pp. 185-196.

19. Martínez-Garcia, E.; Raya, J.M. Length of stay for low-cost tourism. Tour. Manag. 2008, 29, 1064-1075. [CrossRef]

20. Peypoch, N.; Randriamboarison, R.; Rasoamananjara, F.; Solonandrasana, B. The length of stay of tourists in Madagascar. Tour. Manag. 2012, 33, 1230-1235. [CrossRef]

21. Thrane, C. Analyzing tourists' length of stay at destinations with survival models: A constructive critique based on a case study. Tour. Manag. 2012, 33, 126-132. [CrossRef]

22. Kiefer, N. Economic duration data and hazard functions. J. Econ. Lit. 1988, 26, 646-667.

23. Garau, C. Perspectives on Cultural and Sustainable Rural Tourism in a Smart Region: The Case Study of Marmilla in Sardinia (Italy). Sustainability 2015, 7, 6412-6434. [CrossRef] 